\title{
Identity of biocrust species and microbial communities drive the response of soil multifunctionality to simulated global change
}

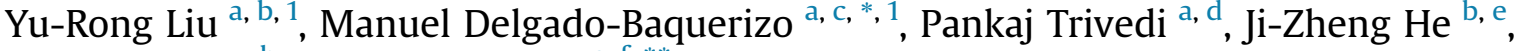 \\ Jun-Tao Wang ${ }^{\mathrm{b}}$, Brajesh K. Singh ${ }^{\mathrm{a}, \mathrm{f}, * *}$ \\ ${ }^{a}$ Hawkesbury Institute for the Environment, Western Sydney University, Penrith South DC, NSW 2751, Australia \\ ${ }^{\mathrm{b}}$ State Key Laboratory of Urban and Regional Ecology, Research Center for Eco-Environmental Sciences, Chinese Academy of Sciences, Beijing 100085, China \\ ${ }^{c}$ Cooperative Institute for Research in Environmental Sciences, University of Colorado, Boulder, CO 80309, USA \\ d Department of Bioagricultural Sciences and Pest Management, Colorado State University, Fort Collins, CO 80523, USA \\ e Faculty of Veterinary and Agricultural Sciences, The University of Melbourne, Parkville, Victoria 3010, Australia \\ ${ }^{\mathrm{f}}$ Global Centre for Land-Based Innovation, Western Sydney University, Penrith South DC, NSW 2751, Australia
}

\section{A R T I C L E I N F O}

\section{Article history:}

Received 24 June 2016

Received in revised form

2 December 2016

Accepted 10 December 2016

Available online 23 January 2017

\section{Keywords:}

Microbial diversity

Bacterial community

Global change

Lichens

Ecosystem functioning

Drylands

\begin{abstract}
A B S T R A C T
Increasing $\mathrm{N}$ inputs and changing rainfall regimes will lead to drastic changes in multiple ecosystem functions such as nutrient cycling, organic matter decomposition and gas exchange in dryland ecosystems. As fundamental components of drylands, biological soil crusts (biocrusts) play important roles in the regulation of responses of multiple ecosystem functions to global environmental changes. Biocrusts are home to highly functional microbial communities; however little is known on the role of microbial communities associated with different biocrust species in regulating the response of multiple ecosystem functions to global change. Here, we conducted a microcosm experiment to evaluate the roles of biocrust-forming lichens (Diploschistes thunbergianus, Psora crystallifera and Xanthoparmelia reptans) in mediating the effects of simulated changes in rainfall frequency and nitrogen $(\mathrm{N})$ addition on soil multifunctionality involving nutrient availability, greenhouse gas flux and enzyme activities. The three biocrust species supported different levels of soil bacterial diversity, and specific community composition as revealed by MiSeq sequencing. Biocrust species always promoted multiple functions related to carbon, nitrogen and phosphorus cycling compared to bare ground, with $X$. reptans having the highest effect on multifunctionality. Most importantly, the relative abundance of specific microbial communities associated with different lichen species modulates the response of multifunctionality to impacts of water frequency (negative) and $\mathrm{N}$ addition (positive). Our results suggest that biocrust species could regulate global change impacts on soil multifunctionality in drylands, although the strength and direction vary among the biocrust species. These findings highlight the importance of preserving biocrusts as hotspots of microbial genetic resources and ecosystem functioning in drylands.
\end{abstract}

() 2016 Elsevier Ltd. All rights reserved.

\section{Introduction}

Drylands ecosystems are one of the most important biomes for global sustainability (Reynolds et al., 2007; Canfora et al., 2014,

\footnotetext{
* Corresponding author. Hawkesbury Institute for the Environment, Western Sydney University, Penrith South DC, NSW 2751, Australia.

** Corresponding author. Global Centre for Land-Based Innovation, Western Sydney University, Penrith South DC, NSW 2751, Australia.

E-mail addresses: M.DelgadoBaquerizo@gmail.com (M. Delgado-Baquerizo), b. singh@westernsydney.edu.au (B.K. Singh).

1 Equal author contribution.
}

2016). Predicted changes in rainfall regime could negatively influence soil biodiversity, essential ecosystem functions and services such as nutrient cycling and plant production in drylands (Wardle et al., 2004; Solomon, 2007; Maestre et al., 2015a; DelgadoBaquerizo et al., 2016a). In addition to climate change, elevated nitrogen $(\mathrm{N})$ inputs from anthropogenic sources into drylands are simultaneously influencing ecosystems (Delgado-Baquerizo et al., 2016a), and reducing soil microbial diversity or altering community composition (Allison et al., 2008; Ramirez et al., 2010, 2012). Understanding the interactive effects of the global change drivers (e.g. altered rainfall patterns or $\mathrm{N}$ inputs) on soil microbial communities and ecosystem processes is essential to develop predictive 
frameworks for protecting ecosystem functioning under changing environments in drylands (Roose et al., 2016).

Biological soil crusts (biocrusts hereafter) are communities of mosses, lichens, cyanobacteria, and heterotrophs that colonize the surfaces of dryland soils (Belnap, 2003; Canfora et al., 2016), that can constitute up to $70 \%$ of the biotic cover of drylands (Belnap, 2003; Maestre et al., 2013; Ferrenberg et al., 2015). A growing body of literature had demonstrated that biocrusts (i.e. species and cover) are essential for the stability and productivity of dryland ecosystems, as they drive multiple ecosystem functions such as nutrient cycling and organic matter decomposition (Eldridge and Greene, 1994; Belnap, 2003; Yoshitake et al., 2010; Maestre et al., 2012a). In addition, previous studies had indicated the effect of biocrust species in controlling the total abundance and composition of soil microbial communities (Bates et al., 2012; Maier et al., 2014; Maestre et al., 2015b). Most important to our topic, biocrusts have been shown to play an essential role in controlling the response of ecosystem functioning to climate change (Reed et al., 2012; Maestre et al., 2013). For instance, a recent study highlighted the important role of biocrust-forming mosses in mitigating the negative impacts of global change (increasing aridity) on ecosystem multifunctionality (DelgadoBaquerizo et al., 2016c). In addition, species identity of biocrustforming lichens modulated the response of soil processes (i.e. $\mathrm{N}$ cycling) to global change drivers (Liu et al., 2016). However, much less is known on the role of identity of biocrust species in regulating the response of ecosystem multifunctionality to global change. The response of soil microbial diversity and ecosystem multifunctionality associated with different biocrust species to global change (e. g. $\mathrm{N}$ inputs and changing rainfall frequency) remains largely unknown.

Biodiversity is a key factor regulating ecosystem functioning (Tilman et al., 1996, 2001; Jing et al., 2015), and loss of biodiversity is considered a major threat to ecosystem services (Hector et al., 1999; Wagg et al., 2014). However, our understanding of the relationship between microbial diversity and ecosystem functioning is much more limited. An increasing number of studies have provided evidence that microbial communities directly influence ecosystem functions and services in terrestrial ecosystems (Berg and Smalla, 2009; Singh et al., 2010; Bodelier, 2011; Trivedi et al., 2013; Bardgett and van der Putten, 2014; Wagg et al., 2014; DelgadoBaquerizo et al., 2016b). These functions include, but are limited to, decomposition of organic matter, nutrient acquisition and the regulation of greenhouse gas emissions. The different microbial communities living under different species of biocrusts may then greatly influence the response of soil functioning to global environmental change. Thus, given the importance of biocrusts for the sustainability of global drylands (Elbert et al., 2012), understanding the role of the microbial communities inhabiting the biocrusts is of paramount importance to predict the response of multiple ecosystem functions to on-going global changes.

Herein, we hypothesized that: i) identity of biocrust species will regulate the response of soil bacterial community to changes in $\mathrm{N}$ addition and rainfall frequency; and ii) microbial diversity and composition associated with different biocrust species will differentially modulate the response of multiple ecosystems functions to global change impacts. To test these hypotheses, we conducted a microcosm experiment to examine the potential direct and indirect (via microbial communities) role of biocrusts species, including Diploschistes thunbergianus, Psora crystallifera and Xanthoparmelia reptans, in mediating responses of soil multifunctionality (i.e. 15 functions involved in nutrient cycling and the regulation of greenhouse gas emission) to simultaneous changes in $\mathrm{N}$ amendment and precipitation frequency.

\section{Materials and methods}

\subsection{Experimental design}

For the microcosm experiment, we collected 120 soil cores $\left(0-5 \mathrm{~cm}\right.$ depth) from a semiarid area of Nyngan $\left(31^{\circ} 34^{\prime}, 147^{\circ} 12^{\prime} \mathrm{E}\right)$, New South Wales, Australia, where open areas between plant patches contained well-developed biocrust communities. The sampled soil cores covered with three lichens studied: $D$. thunbergianus, $P$. crystallifera and $X$. reptans. Each pot exclusively contains either bare ground, D. thunbergianus, $P$. crystallifera or $X$. reptans. Basic chemical characteristics of the soils before our incubation experiment are listed in Table S1. The experimental design had been described in detail previously in Liu et al. (2016). In brief, we established a microcosm study with a full factorial experimental design including three factors: identity of biocrusts species (D. thunbergianus, $P$. crystallifera and $X$. reptans), $\mathrm{N}$ amendment aligned with reported rates for $\mathrm{N}$ deposition ( 0 and $20 \mathrm{~kg} \mathrm{~N} \mathrm{ha}^{-1}$ year $^{-1}$ ) and altered water frequency (i.e. high frequency, $3.61 \mathrm{~mm}$ each 3 days; moderate frequency, $7.22 \mathrm{~mm}$ each 6 days; and low frequency, $14.44 \mathrm{~mm}$ each 12 days). Bare soil was also treated as a procedure control vs. lichen species under the simulated global change conditions. The total amount of watering to these soil cores by the end of the experiment is exactly the same regardless of the altered frequency, which was adjusted to mimic the rainfall level during the spring season of previous year under field conditions. Moreover, $\mathrm{N}$ was added at the beginning of the experiment by dissolving $\mathrm{NH}_{4} \mathrm{NO}_{3}$ in water. The $\mathrm{N}$ addition and watering treatments were established to test whether biocrustforming lichens can potentially drive the response of belowground bacterial community and ecosystem multifunctionality to the global change drivers. Five replicated cores per combination of treatments were incubated for 72 days in a climate-controlled glass-house. Full details of incubation conditions are provided in the methods description within the Supplementary information. After the incubation, soil samples $(0-4 \mathrm{~cm}$ depth) from different treatments were collected, carefully removing the above biocrusts. All the soil samples were mixed homogenously and passed through a $2.0 \mathrm{~mm}$ sieve, which were subsequently divided into two subsamples. One sub-sample was stored at $-20^{\circ} \mathrm{C}$ for microbial DNA extraction, and another sub-sample was stored at $4{ }^{\circ} \mathrm{C}$ for the assessment of soil functions.

\subsection{Single soil function analysis}

In total, we tested for 15 soil variables as key ecosystem functions including (1) available nitrogen (AN), (2) potential nitrification rate (PNR), (3) microbial biomass $\mathrm{N}$ (MBN), (4) dissolved organic carbon (DOC), (5) microbial biomass carbon (MBC), (6) $\mathrm{CO}_{2}$ flux, (7) $\mathrm{CH}_{4}$ flux, (8) $\mathrm{N}_{2} \mathrm{O}$ flux, (9) $\beta$-D-glucopyranoside (BG), (10) $\beta$ D-cellulosidase (CB), (11) $\beta$-xylosidase (XYL), (12) $\alpha$-glucosidase (AG), (13) L-Leucine-7-amido-4-methylcoumarin hydrochloride (LAP), (14) phosphate (PHOS), and (15) $N$-acetyl- $\beta$-glucosaminidase (NAG). These selected variables are related to cycling of nitrogen $(\mathrm{N})$, carbon $(\mathrm{C})$ and phosphate $(\mathrm{P})$, and the regulation of greenhouse gas emissions. Dissolved organic carbon and $\mathrm{AN}$ in the soils were extracted with $0.5 \mathrm{M} \mathrm{K}_{2} \mathrm{SO}_{4}$ in a ratio $1: 5$ by shaking at $200 \mathrm{rpm}$ for $1 \mathrm{~h}$ and filtered using $0.45-\mu \mathrm{m}$ Millipore filter paper (Liu et al., 2016). In parallel, the carbon in microbial biomass (MBC) and the $\mathrm{N}$ in microbial biomass (MBN) were evaluated using the fumigation-extraction method (Brookes et al., 1985; Vance et al., 1987). The selected enzyme activities including BG, CB, XYL, AG, LAP, PHOS and NAG were measured using 4-methyl umbelliferyl (MUB) substrate yielding the highly fluorescent cleavage products MUB upon hydrolysis (Wallenstein and Weintraub, 2008). 
Greenhouse gas $\left(\mathrm{CH}_{4}, \mathrm{~N}_{2} \mathrm{O}\right.$ and $\left.\mathrm{CO}_{2}\right)$ flux was monitored with a whole soil column including soil and biocrusts. Full details of these soil function measurements are provided in the methods description within the Supplementary information.

\subsection{Soil DNA extraction and quantification of $16 S$ rRNA gene abundance}

The total genomic DNA was isolated from $0.25 \mathrm{~g}$ of soil using the MoBio PowerSoil DNA Isolation Kit (MoBio Laboratories, Carlsbad, CA, USA) following to the manufacturer's instructions. The concentration and quality of extracted DNA was checked photometrically using a NanoDrop ${ }^{\mathbb{B}}$ ND-2000c UV-Vis spectrophotometer (NanoDrop Technologies, Wilmington, DE, USA). Bacterial 16S rRNA gene abundance was quantified by qPCR on a CFX-96 thermocycler (Biorad, USA) using primer pairs of Eub338F/Eub518R (Cregger et al., 2012), The $10 \mu \mathrm{l}$ reaction mixture contained $5 \mu$ l SensiMix SYBR No-ROX reagent (Bioline, Sydney, Australia), $0.3 \mu \mathrm{l}$ of each primer $(20 \mathrm{mM}), 0.4 \mu \mathrm{l} \mathrm{BSA}(20 \mathrm{mM})$, and $1 \mu \mathrm{l}$ of diluted template DNA (1-10 ng). Thermal-cycling conditions were as follows: 5 min initial denaturation at $95^{\circ} \mathrm{C}, 40$ cycles of $30 \mathrm{~s}$ at $95^{\circ} \mathrm{C}, 30 \mathrm{~s}$ at $55^{\circ} \mathrm{C}$, $1 \mathrm{~min}$ at $72^{\circ} \mathrm{C}$, followed by a plate read at $83^{\circ} \mathrm{C}$. The PCR amplicons were ligated into a pGEM-T Easy vector (Promega, USA) and transformed into Escherichia coli JM109 cells. Plasmid containing $16 S$ rRNA gene was used as standard template, and standard curve were generated with 10 -fold serial dilutions of the plasmid. Melt curve analyses were conducted following each assay to verify the specificity of the amplification products, and the PCR efficiency of standard curve for different assays ranged between $89 \%$ and $99 \%$.

\subsection{Bacterial community composition analysis}

To evaluate the bacterial community composition, we amplified the $\mathrm{V} 4$ region of the bacterial $16 S$ rRNA gene with the primer pairs of $341 \mathrm{~F} / 805 \mathrm{R}$ on Illumina MiSeq platform of the Western Sydney University (Herlemann et al., 2011; Delgado-Baquerizo et al., 2016b). Primer sequences were modified by adding Illumina adaptor $\mathrm{A}$ to the $5^{\prime}$-ends of the forward primers, and adaptor $\mathrm{B}$ followed by 12 nucleotide barcode sequences to the $3^{\prime}$-ends of the reverse primers. Raw sequences generated through MiSeq pairedend sequencing were merged using fast length adjustment of short reads (FLASH) (Magoč and Salzberg, 2011) with Q30 of clean full-length reads ranging from 95.0 to $95.8 \%$. A chimera filtering approach (UPARSE), was used to pick operational taxonomic units (OTUs) at $97 \%$ similarity on the Bio-Linux platform. Representative sequences were processed using the QIIME pipeline (Edgar, 2013). PyNAST alignment, and ribosomal database project (RDP) assignment were carried out based on the latest Green genes database (McDonald et al., 2012). Resampling according to the minimum sequence numbers across all samples was performed before downstream analyses. Bacterial species richness and Shannon diversity index were calculated based on $97 \%$ OTU similarity of obtained bacterial sequences. The community composition provides the classification information at phylum level across the soils from different treatments.

\subsection{Assessing multifunctionality}

To obtain a quantitative multifunctionality index for each treatment, we first normalized (log-transformed when needed) and standardized each of the 15 functions measured using the Zscore transformation. These standardized ecosystem functions were then averaged to obtain a multifunctionality index as described in (Maestre et al., 2012b). This index is now largely used in the current literature and allows us to explore the role of biocrust species, microbial communities and global change on multiple ecosystem functions simultaneously, instead of focusing on one or several functions that would not be representative of a natural ecosystem. A greater value of ecosystem functions reflects a more desirable aspect of the ecosystem. $\mathrm{CH}_{4}$ and $\mathrm{N}_{2} \mathrm{O}$ production were multiplied by -1 (inverted around the 0 mean) to maintain directional change with other ecosystem functions, such that a decline from their desirable state corresponds to increasingly negative values. By doing this the general difference among biocrusts and global change treatments in overall ecosystem functioning could be more easily assessed.

\subsection{Statistical analysis}

We used ANOVA to test for differences of the effect in identity of biocrust species, water frequency and $\mathrm{N}$ addition treatment on the bacterial community (total abundance, diversity and relative abundance of main phyla/classes) and soil multifunctionality. The $16 S$ rRNA gene copy numbers were log-transformed prior to statistical analysis to meet normality assumptions. Due to the high amount of data derived from MiSeq sequence analyses, we first preselected those groups highly related to soil functionality, hence are able to explain an indirect impact of identity of biocrust species on multifunctionality via relative abundance of microbes. To do this, we conducted a Random Forest analysis to identify the important bacterial predictors (at a phylum/class level) of multifunctionality as explained previously (Delgado-Baquerizo et al., 2016c; Trivedi et al., 2016). After this, Spearman's correlation analyses were performed to assess the relationships between relative abundace of major bacterial predictors of multifunctionality and single functions studied. All statistical analyses were performed using R.3.2 software (http://www.r-projext.org). Note that we conducted our analysis at phyla/class level for two main reason: 1) the use of high bacterial taxonomic ranks (phylum and class) have been highly recommended to predict patterns in ecosystem functioning (Philippot et al., 2010; Trivedi et al., 2013); 2) functional information has become increasingly available at these taxonomic levels (Fierer et al., 2007; Trivedi et al., 2013).

We then used structural equation modelling (SEM) to evaluate the direct and indirect effect of the identity of biocrust species, global change (altered rainfall frequency and $\mathrm{N}$ amendment), and bacterial communities (i.e. composition, richness and abundance) on soil multifunctionality. The $\mathrm{N}$ treatments were set as categorical exogenous variables with two levels: 0 and 1 (Grace, 2006). In the model, the different biocrust-forming lichens species (D. thunbergianus, $P$. crystallifera and $X$. reptans were categorical variables with two levels: 0 (specific species) and 1 (remaining species + bare soil). Bare soil was included as our procedural control in these models. This approach allowed us to compare the effect of a particular biocrust species (e. g. D. thunbergianus) on the bacterial community and multifunctionality compared with the average of the remaining microsites. Note that bare soil was selected as our baseline condition, and was not included explicitly in our model (Grace, 2006). We included bacterial abundance, richness and composition (i.e. relative abundance of bacterial communities pre-selected from Random Forest analyses) in the model. Bacterial composition was included as a composite variable in our model (Grace, 2006). The data matrix was fitted to the model using the maximum-likelihood estimation method. There is no single universally accepted test of overall goodness of fit for SEM. Thus, we used the Chi-square test $\left(\chi^{2}\right.$; the model has a good fit when $0 \leq \chi^{2} \leq 2$ and $0.05<P \leq 1.00$ ) and the root mean square error of approximation (RMSEA; the model has a good fit when RMSEA $0 \leq$ RMSEA $\leq 0.05$ and $0.10<P \leq 1.00$ (Schermelleh-Engel et al., 2003). The different goodness-of-fit metrics indicated that 
our a priori model satisfactorily fit to our data, and thus no post hoc alterations were made. To aid with the final interpretation of the SEM, we also calculated the standardized total effects of the biocrust species, global change drivers and microbial community features on ecosystem multifunctionality. The net influence that a given variable has upon another was calculated by summing all direct and indirect pathways between these two variables. SEM analyses were done using AMOS 21.0 (SPSS Inc., Chicago, IL, USA).

\section{Results}

\subsection{Soil multifunctionality under the three biocrust-forming lichens}

The results indicate that soils beneath different biocrustforming lichens showed differential soil multifunctionality responses to simulated global change (Fig. 1), which correlated to most of the examined single functions associated with cycling of $\mathrm{C}$, $\mathrm{N}$ and $\mathrm{P}$ (Table S2). Soils under biocrusts had a higher multifunctionality index than bare soils, with the highest multifunctionality index being under $X$. reptans. However, multifunctionality was also affected by added $\mathrm{N}$ and its interactions with altered rainfall frequency $(P<0.001$, Fig. 1 ; Table S3). In particular, $\mathrm{N}$ addition increased soil multifunctionality under $D$. thunbergianus and $P$. crystallifera, while negative effects were found for $X$. reptans under low water frequency $(P<0.05$, Fig. 1 ; Table S4).

\subsection{Soil bacterial diversity and abundance}

A total of 3553 bacterial OTUs were characterized using a $97 \%$ sequence similarity cutoff from roughly 8.6 million high quality sequences. Bacterial diversity level was significantly influenced by the species identity of biocrust as proven by the examined richness of OTU-based observed species and the quantitative Shannon's index $(P<0.05$, Fig. 2; Fig. S1; Table S3); soils under $X$. reptans had the highest bacterial species richness $(P<0.01)$. Additional $\mathrm{N}$ had a negative effect on soil bacterial richness, especially remarkable under $X$. reptans and the bare ground $(P<0.01$, Table $S 4)$. Importantly we found an interactive effect of altered rainfall frequency and $\mathrm{N}$ amendment on bacterial richness $(P<0.05$, Table S3). There is no significant differences of bacterial abundance in the soils under bare ground and the three biocrust species (Fig. 2; Table S3), while biocrusts and rainfall frequency had interactive effects on

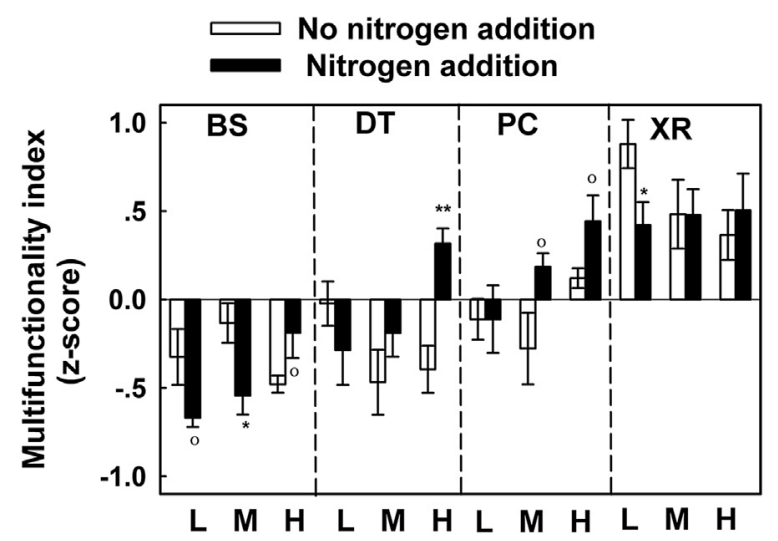

Fig. 1. Multifunctionality index in response to altered watering frequency and $\mathrm{N}$ addition in bare soil (BS) and soils under different biocrust-forming lichen species: Diploschistes thunbergianus (DT), Psora crystallifera (PC), and Xanthoparmelia reptans (XR). Differences between $\mathrm{N}$ amendment and the control for each examined variable are as follows: ${ }^{\circ}, P<0.10 ;{ }^{*}, P<0.05 ;^{* *}, P<0.01$. Data are means \pm SE $(n=5)$.

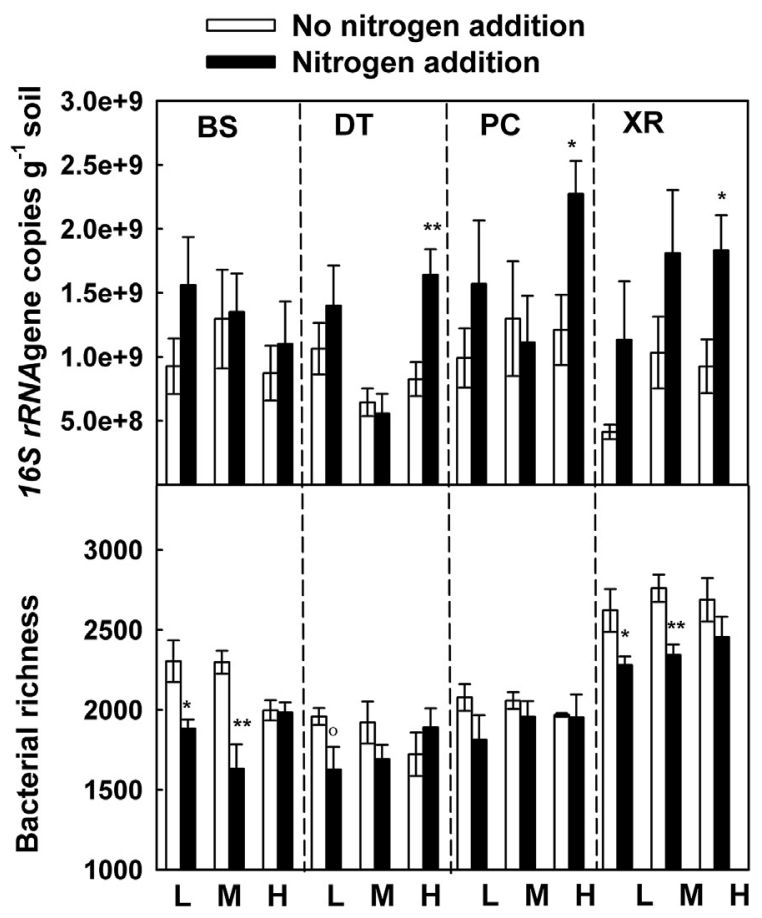

Fig. 2. Soil bacterial abundances and richness in response to added nitrogen $(\mathrm{N})$ and altered watering frequency in the bare soil (BS) and soils under different biocrustforming lichen species: Diploschistes thunbergianus (DT), Psora crystallifera (PC) and Xanthoparmelia reptans (XR); and bare soil (BS). Letter L, M and $\mathrm{H}$ mean low (added water each 12 days), moderate (added water each 6 days) and high watering frequency (added water each 3 days), respectively. Differences between $\mathrm{N}$ amendment and the control for each examined variable are as follows: ${ }^{\circ}, P<0.10$; ${ }^{*}, P<0.05$; $^{* *}, P<0.01$. Data are means \pm SE $(n=5)$.

bacterial abundance $(P<0.05$, Table S3). Individually, additional $\mathrm{N}$ and increased rainfall frequency had positive effects on soil bacterial abundance under $X$. reptans $(P<0.01$; Table S4), while the two global change drivers had no overall influence on soil bacterial abundance under $D$. thunbergianus or $P$. crystallifera $(P>0.05$; Table S4).

\subsection{Shifts in bacterial community composition}

Most of the bacterial OTUs were classified as Chloroflexi (25\%), Actinobacteria (21\%), Proteobacteria (18\%), Acidobacteria (12\%), Planctomycetes (10\%), although their relative abundance varied under the different biocrust species (Fig. S2). We identified the most important bacterial phyla as predictors of multifunctionality based on Random Forest modelling. Our results show that Chloroflexi, Cyanobacteria, $\alpha$-Proteobacteria, $\delta$-Proteobacteria and Bacteroidetes were major bacterial predictors of multifunctionality (Fig. S3). Biocrust species significantly affected the relative abundance of all five major bacterial predictors $(P<0.01$, Fig. 3 and Table S3), especially for Chloroflexi with the lowest relative abundance under $X$. reptans. The $\mathrm{N}$ addition had overall effects on the relative abundance of $\delta$-Proteobacteria and Bacteroidetes, and its interaction with rainfall frequency influenced all of the predictors except for $\alpha$-Proteobacteria (Fig. 3 and Table S3). However, the impact patterns of these global change drivers on the predictors varied under different lichens. For instance, added $\mathrm{N}$ tended to reduce the relative abundance of Cyanobacteria, $\delta$-Proteobacteria and Bacteroidetes under $P$. crystallifera $(P<0.10$, Table S4), while no similar negative effect was observed under $D$. thunbergianus and $X$. reptans. We also found an interactive effect of the two global change drivers on all bacterial predictors except $\alpha$-Proteobacteria 

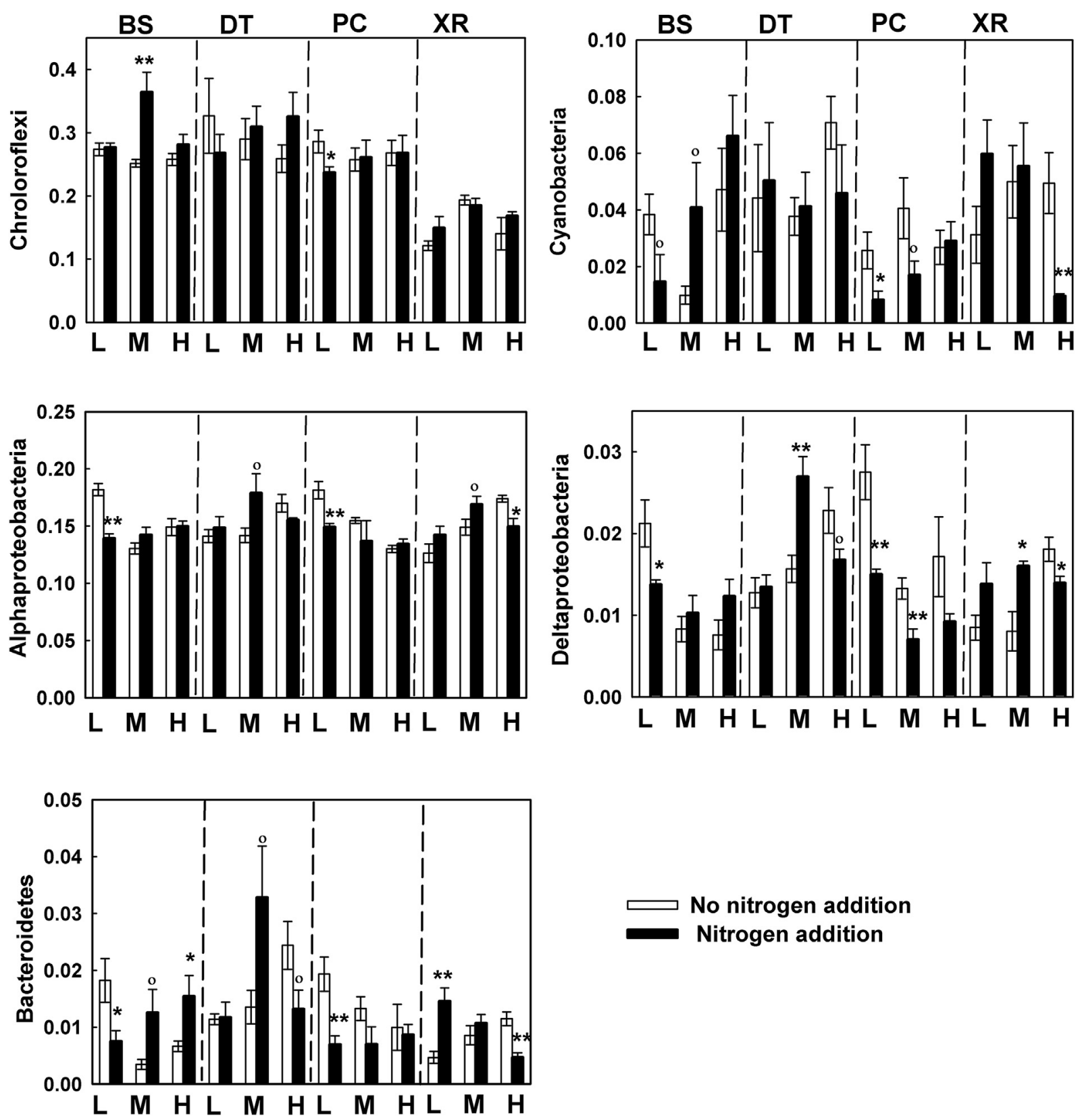

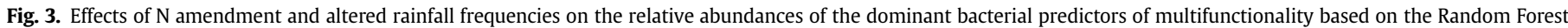

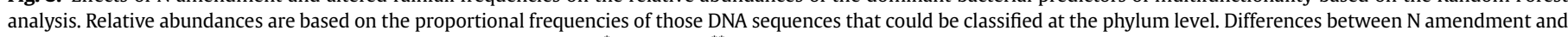

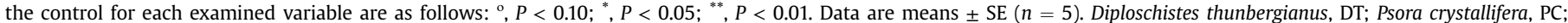
Xanthoparmelia reptans, XR; and bare soil, BS.

$(P<0.10$, Table $\mathrm{S} 3)$. Changes in $\mathrm{N}$ amendment and rainfall frequency had significant effects on the community structure of the bacterial predictors (PerMANOVA, $P<0.05$, Fig. S4).

\subsection{Direct and indirect impact of identity of biocrust species, microbial communities and global change on multifunctionality}

Our SEM explained $60 \%$ of the variance in soil multifunctionality, which demonstrates overall positive effects of the three biocrust species on soil multifunctionality (vs bare ground, included as control procedure; $P<0.01$, Fig. 4 a). D. thunbergianus and $X$. reptans showed the highest and lowest direct (or total) effect on multifunctionality, respectively (Fig. 4a and b). Interestingly, all the biocrust species showed indirect effects on multifunctionality via microbial composition, but not richness or total abundance. The bacterial groups involved in these indirect effects seem to be highly dependent on species identity of biocrusts. For instance, $P$. crystallifera and $X$. reptans, but not $D$. thunbergianus, showed positive and negative indirect effects on multifunctionality via the relative abundance of Bacteroidetes and Chloroflexi, respectively. Interestingly, the relative abundance of $\delta$-Proteobacteria, and $\alpha$ Proteobacteria showed differential effects on multifunctionality for the different biocrust species: $X$. reptans (positive), $D$. thunbergianus (negative) and $P$. crystallifera (null effect). Only the relative abundance of Cyanobacteria showed a constant positive direct effect on multifunctionality for all biocrust species (Fig. 4a). 


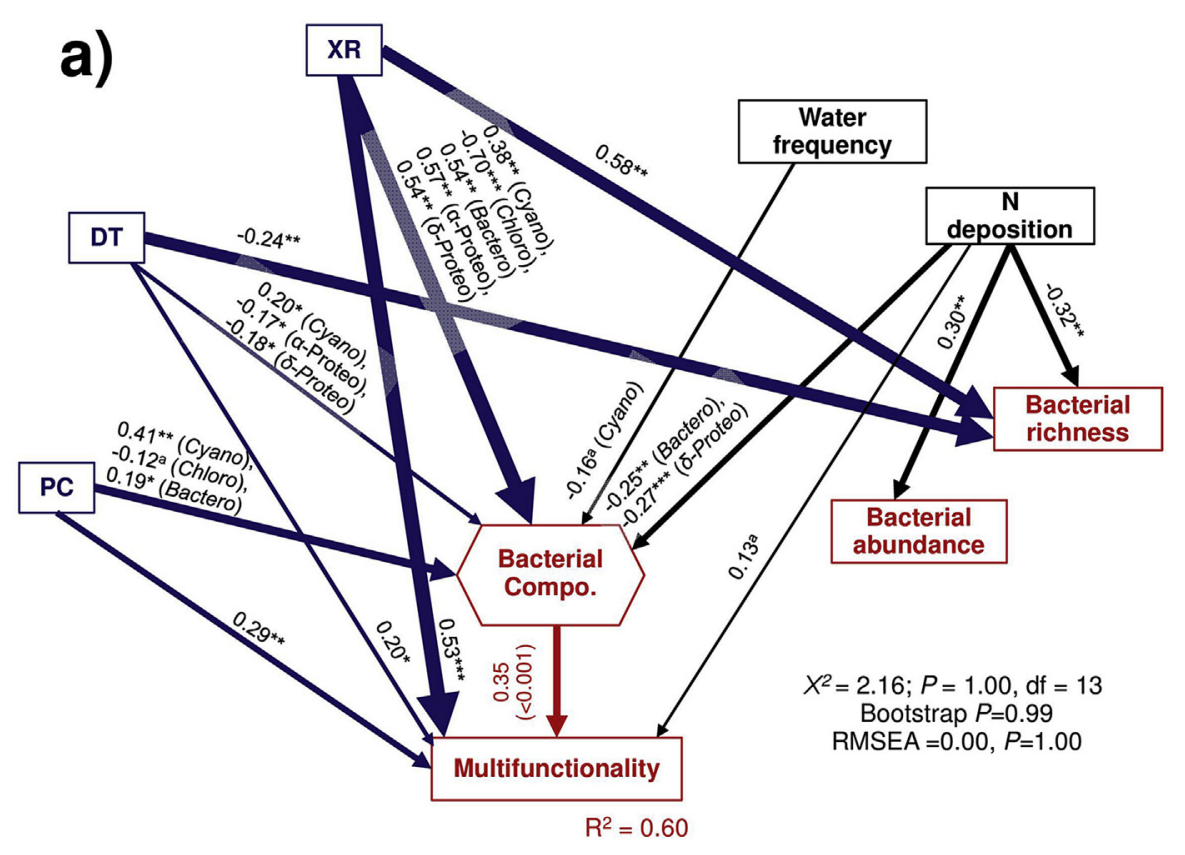

b)

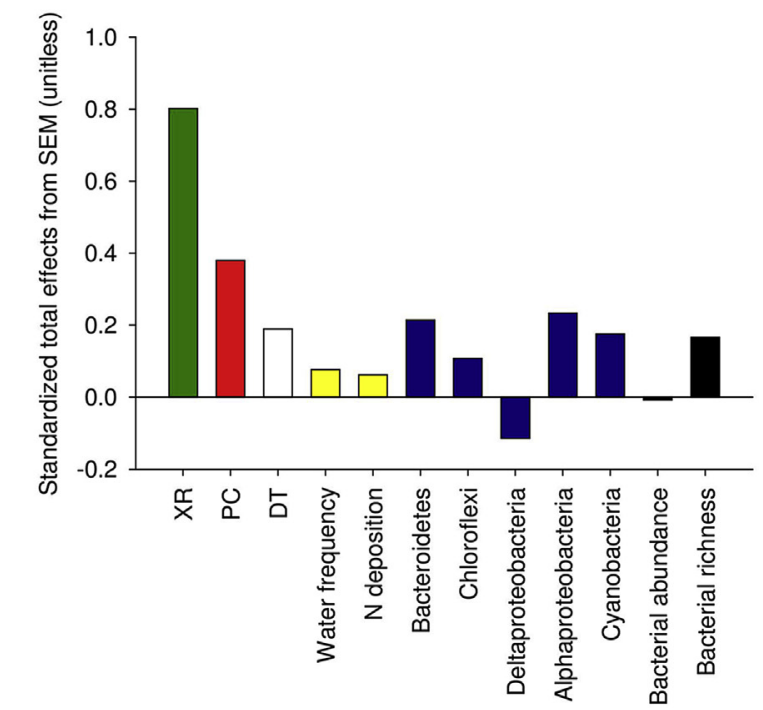

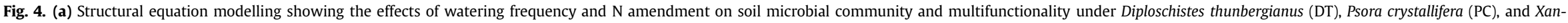

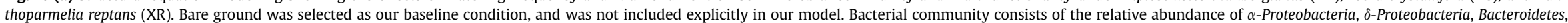

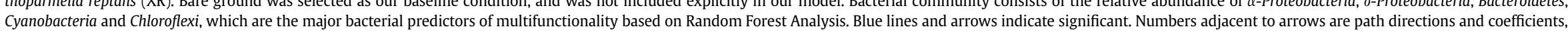

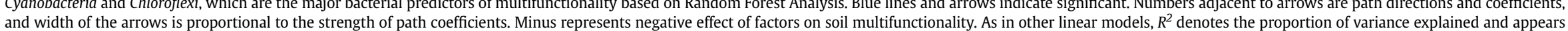

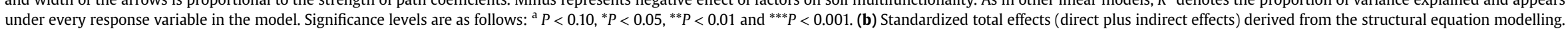
under every response variable in the model. Significance levels are as follows: ${ }^{a} P<0.10,{ }^{n} P<0.05,{ }^{n} P<0.01$ and
(For interpretation of the references to colour in this figure legend, the reader is referred to the web version of this article.) 
Water frequency and $\mathrm{N}$ amendment had indirect negative effects on the multifunctionality through the different bacterial community composition. The added $\mathrm{N}$ indirectly influenced soil multifunctionality via Bacteroidetes and $\delta$-Proteobacteria, while altered water frequency had a negative effect via Cyanobacteria. However, those global change impacts on soil multifunctionality could be mitigated by the biocrust-forming lichens in this order: $X$. reptans $>P$. crystallifera $>D$. thunbergianus, as the total positive effects from these lichens on multifunctionality was higher (D. thunbergianus and P. crystallifera) and much higher (X. reptans) than any negative/positive impact of altered water frequency and $\mathrm{N}$ amendment on multifunctionality (Fig. 4b).

\section{Discussion}

\subsection{Biocrust-forming lichens indirectly drive multifunctionality via} microbial communities

Our results demonstrate that all three biocrust-forming lichens enhanced soil multifunctionality in this study, and that the positive effects of identity of biocrust species can differentially (X. reptans $>P$. crystallifera $>D$. thunbergianus) buffer the global change impacts on multifunctionality. These findings are in agreement with the growing idea that biocrusts promote the resistance and stability of ecosystem-multifunctionality in response to global change (Reed et al., 2012; Maestre et al., 2013; Delgado-Baquerizo et al., 2016c), but further indicate that the identity of biocrusts needs to be considered to properly assess their role in regulating the responses of multifunctionality to global change.

In this case, $X$. reptans had higher direct and indirect (via microbial composition) positive effects on soil multifunctionality, compared with $D$. thunbergianus and $P$. crystallifera. Identity of biocrusts could influence the responses of multifunctionality to global change in several ways including through indirect control via microbial communities (studied here), lichen traits and/or soil properties. A large body of literature has demonstrated key roles of microbial communities in regulating belowground ecosystem functions and services (Bardgett and van der Putten, 2014; Wagg et al., 2014; Jing et al., 2015; Delgado-Baquerizo et al., 2016b). Here, we included bacterial richness, abundance and community composition of the major bacterial predictors to explore their relative contributions to soil multifunctionality. Bacterial richness and abundance had little effect on soil multifunctionality in the present study, while the bacterial community composition (major predictors of multifunctionality) linked to the aboveground biocrust species plays crucial roles in driving ecosystem multifunctionality (Fig. 4a and b). Correlation of these dominant predictors with each single function also demonstrates the significance of the bacterial predictors in controlling soil functions (Table 1). These findings further support the accumulating evidence that soil community composition could be a key factor regulating ecosystem functioning (Bell et al., 2005; Wagg et al., 2014). The positive effects of Bacteroidetes and Cyanobacteria on soil multifunctionality suggest that these phyla dominated communities linked with biocrusts, may enhance ecosystem functions and services. On the contrary, Chloroflexi could impair ecosystem processes in drylands. Shifts in bacterial community composition driven by aboveground biocrust species could be particularly significant for ecosystem multifunctionality in dryland ecosystems (DelgadoBaquerizo et al., 2016c).

The results from this study showed overall positive effects of the bacterial community on the soil multifunctionality involved in nutrient cycling and greenhouse gas flux regulation, which could be elucidated by similar positive trends for most of the single variables associated with cycling of $\mathrm{C}$ and $\mathrm{N}$. Interestingly, we found only negative correlations of Chloroflexi with most of examined functional variables (e.g. $\mathrm{CO}_{2}$ emission), agreeing with a previous study suggesting the potential role of Chloroflexi in $\mathrm{CO}_{2}$ fixation (Hug et al., 2013). However, we found the lowest relative abundance of Chloroflexi under $X$. reptans, and this may partially explain the highest positive effect of $X$. reptans on soil multifunctionality. Chloroflexi are believed to have multiple adaptations to harsh environments and were negatively correlated to soil $\mathrm{C}$ in drylands (Battistuzzi and Hedges, 2009; Maestre et al., 2015a). These observations probably explain the relatively high abundance of Chloroflexi under $D$. thunbergianus where soils had relatively low nutrient status as reported previously (Liu et al., 2016). These findings further emphasize the great importance of microbial communities on ecosystem processes such as the cycles of $\mathrm{C}$ and $\mathrm{N}$ (Anderson and Domsch, 1989; Jiao et al., 2010; Kraft et al., 2014). However it should be noted that little effect was observed on the activity of phosphatase which is an important indicator of soil $\mathrm{P}$ cycling. These observations are in line with previous studies suggesting lower sensitivity of $\mathrm{P}$ cycling to global change than the turnover of $\mathrm{C}$ and $\mathrm{N}$ due to the dissolution of $\mathrm{P}$ from soil minerals (Walker and Syers, 1976; McGill and Cole, 1981; Delgado-Baquerizo et al., 2016c). The different impact patterns of the three biocrust species on soil multifunctionality could also be a consequence of different soil properties related to their species identity of biocrust-

Table 1

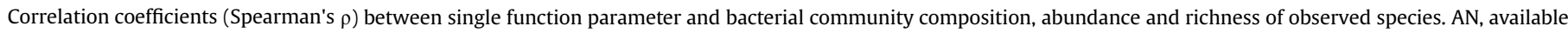

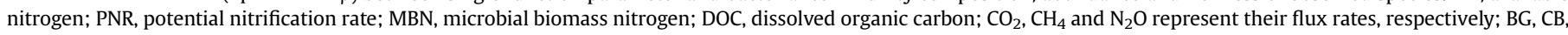

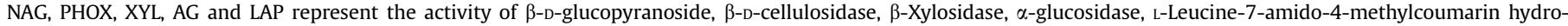
chloride, phosphate, and $N$-acetyl- $\beta$-glucosaminidase, respectively. $P$ values below 0.05 are in bold.

\begin{tabular}{|c|c|c|c|c|c|c|c|}
\hline & Abundance & Richness & Chloroflexi & Cyanobacteria & Alphaproteobacteria & Deltaproteobacteria & Bacteroidetes \\
\hline AN & 0.83 & $0.22^{*}$ & $-0.40^{* *}$ & $0.28^{* *}$ & $0.38^{* *}$ & 0.08 & $0.28^{*}$ \\
\hline $\mathrm{N}_{2} \mathrm{O}$ & 0.06 & $0.18^{*}$ & -0.16 & $0.30^{* *}$ & 0.14 & 0.13 & $0.20^{*}$ \\
\hline PNR & -0.09 & $0.53^{* *}$ & $-0.59^{* *}$ & 0.08 & $0.63^{* *}$ & $0.51^{* *}$ & $0.24^{* *}$ \\
\hline MBN & -0.16 & $0.48^{* *}$ & $-0.46^{* *}$ & $0.24^{* *}$ & $0.33^{* *}$ & $0.41^{* *}$ & $0.50^{* *}$ \\
\hline DOC & -0.05 & $0.35^{* *}$ & $-0.43^{* *}$ & $0.23^{*}$ & $0.42^{* *}$ & $0.34^{* *}$ & $0.33^{* *}$ \\
\hline $\mathrm{CO}_{2}$ & 0.04 & $0.37^{* *}$ & $-0.40^{* *}$ & 0.19* & $0.23^{*}$ & $0.31^{* *}$ & $0.39^{* *}$ \\
\hline $\mathrm{CH}_{4}$ & 0.07 & -0.16 & 0.17 & -0.15 & -0.07 & -0.09 & -0.14 \\
\hline BG & 0.09 & $0.46^{* *}$ & $-0.47^{* *}$ & $0.32^{* *}$ & $0.31^{* *}$ & $0.42^{* *}$ & $0.53^{* *}$ \\
\hline $\mathrm{CB}$ & -0.01 & $0.37^{* *}$ & $-0.37^{* *}$ & $0.46^{* *}$ & $0.32^{* *}$ & $0.28^{* *}$ & $0.46^{* *}$ \\
\hline NAG & 0.02 & 0.11 & $-0.27^{* *}$ & $0.36^{* *}$ & $0.33^{* *}$ & 0.09 & $0.29^{* *}$ \\
\hline PHOS & 0.17 & -0.05 & 0.09 & 0.02 & -0.10 & -0.06 & 0.07 \\
\hline XYL & 0.07 & $0.26^{* *}$ & $-0.39^{* *}$ & $0.34^{* *}$ & $0.36^{* *}$ & $0.20^{*}$ & $0.34^{* *}$ \\
\hline AG & -0.01 & 0.17 & -0.16 & $0.28^{* *}$ & 0.11 & 0.10 & $0.26^{* *}$ \\
\hline LAP & 0.04 & $0.27^{* *}$ & $-0.31^{* *}$ & $0.20^{*}$ & 0.19* & $0.26^{* *}$ & $0.27^{* *}$ \\
\hline MBC & $-0.19^{*}$ & $0.50^{* *}$ & $-0.57^{* *}$ & $0.34^{* *}$ & $0.47^{* *}$ & $0.42^{* *}$ & $0.60^{* *}$ \\
\hline
\end{tabular}


forming lichens (Bowker and Belnap, 2008; Maestre et al., 2012a; Liu et al., 2016). For example, soils under X. reptans had the highest availability of nutrient before our experiment (Table S1), which may increase the diversity and activities of the microbial community (Fig. S1; Fig. 4). Differentially, D. thunbergianus thalli are firmly attached to the soil (with relatively low nutrient), which may produce local anaerobic conditions (Kidron et al., 2015), influencing the microbial communities involved in ecosystem multifunctionality. The thallus of $P$. crystallifera is also highly attached to the soil, albeit they usually form smaller patches than $D$. thunbergianus and thus may promote more similar conditions to X. reptans (Liu et al., 2016). Consequently, the differences in biocrust species result in altered soil properties and microbial community compositions, which will in turn influence ecosystem multifunctionality in drylands.

\subsection{Relative importance of biocrust species, microbial communities and global change in controlling multifunctionality}

Our results suggest that all three biocrusts, their microbial communities and global change had effects on soil multifunctionality directly or indirectly, though the patterns and direction were varied under different conditions (Fig. $4 a$ and b). The three biocrust species enhanced soil multifunctionality compared to bare ground, while altered rainfall frequency and $\mathrm{N}$ amendment had negative indirect impacts on multifunctionality via bacterial communities. Contemporary global change in this study, for example $\mathrm{N}$ addition, altered the relative dominance of the main bacterial community taxa (Fig. 3; Fig. S3); our results suggest that the major bacterial predictors of multifunctionality such as $\delta$-Proteobacteria and Bacteroidetes are vulnerable to $\mathrm{N}$ addition, which are important for $\mathrm{C}$ and $\mathrm{N}$ cycling, as well as $\mathrm{CO}_{2}$ fluxes according to our results (Table 1 ). Furthermore, interactions between altered water frequency and added $\mathrm{N}$ influenced most of the bacterial predictors, which could have important impacts on soil multifunctionality. Our observations further suggest negative effects of global change on soil microbial communities (Ramirez et al., 2010, 2012; Zeglin et al., 2013; Martins et al., 2015), which are closely related to ecosystem functioning.

Most important to our research topic, the identity of biocrusts and their associated microbial communities play an essential role in regulating the responses of multifunctionality to global change. Of special interest was the positive effect of some biocrust species on soil multifunctionality were considerably larger than the negative effects from the global change drivers through bacterial community (Fig. 4a and b), hence suggesting that maintaining key biocrust species is essential to offset negative effects of global change on ecosystem functioning. This is especially remarkable under $X$. reptans, as our estimate of the effect strength was greater than any other factor influencing soil multifunctionality. Consequently, these positive effects from biocrusts on multifunctionality may offset any impacts from the global change drivers on ecosystem functioning. These observations are further supported by a recent filed study suggesting biocrust-forming mosses mitigate global change impacts (increasing aridity) on soil multifunctionality in drylands (Delgado-Baquerizo et al., 2016c). Thus, biocrust-forming lichens play important roles in buffering global change impacts on ecosystem multiple functions. We argue that biocrusts may be an important shelter protecting ecosystem functions from global change impacts in dryland ecosystems.

Correlations between bacterial richness with many specialized functions further demonstrate the crucial roles of microbial diversity on ecosystem processes (Bell et al., 2005; Peter et al., 2011; Wagg et al., 2014; Delgado-Baquerizo et al., 2016b). Our results indicate the negative effect of added $\mathrm{N}$ on bacterial richness despite the positive effect on soil bacterial abundance (Fig. 1, Table S3). These contrary effects on the bacterial community are similar to those observed in previous studies (Fog, 1988; Sinsabaugh et al., 2015). This suggests that additional $\mathrm{N}$ has a negative effect on to some microbial species, though probably benefits the microbes involved in $\mathrm{N}$ cycling that can utilize freshly spiked $\mathrm{N}$ as a substrate. Consequently, amended $\mathrm{N}$ may enhance microbial abundance while reducing microbial diversity (species richness), thereby influencing ecosystem functioning. These results also indicate that enhanced rainfall frequency reduced the richness under bare ground without $\mathrm{N}$ addition. No similar effects under the three biocrusts were observed suggesting that biocrusts might enhance the resistance of bacterial diversity to the disturbance of altered rainfall frequency. Biocrusts may provide better habitats for microbial communities compared with bare soils, buffering global change impacts on the ecosystem (Delgado-Baquerizo et al., 2016c). Our results are in line with previously reported studies demonstrating the important roles of biocrusts in enhancing ecosystem resistance (Delgado-Baquerizo et al., 2013; Sancho et al., 2014; Escolar et al., 2015). These observations also suggest that biocrust-forming lichens may play crucial roles in relieving negative effects of global change drivers on soil multifunctionality via bacterial communities in drylands. Given important role of fungal communities in regulating soil functions (Tedersoo et al., 2014; Wagg et al., 2014), positive effect of microbial diversity on soil multifunctionality in drylands may have been strengthen (DelgadoBaquerizo et al., 2016b). However, differences in biocrust species could modulate the response of multifunctionality to global change in drylands.

\section{Conclusions}

Taken together, our findings provide evidence that identity of biocrust species and their associated microbial communities regulate the impact of $\mathrm{N}$ addition and altered rainfall frequency on soil multifunctionality. We emphasize the lichen-dominated biocrusts enhanced soil multifunctionality, compared with bare soils. Bacterial communities are important drivers of soil multifunctionality, and shifts in community composition related to aboveground biocrust species may have significant functional consequences in dryland ecosystems; this is also an important mechanism by which biocrusts regulate ecosystem services and delivery. Protecting biocrust species is therefore of paramount importance for buffering global change impacts on microbiallydriven ecosystem multifunctionality in dryland ecosystems. Owing to limitations of the microcosm study, however, further field studies with natural conditions will strengthen our understanding of biocrust regulations on the response of ecosystem multiple functions to global change.

\section{Acknowledgements}

We gratefully acknowledge Raul Ochoa-Hueso for his assistance during field sampling and David Eldridge for help identifying biocrust species. We thank Catriona A. Macdonald and Yui Osanai for their help in chemical analysis and measurement of greenhouse gas, and the NGS team from Western Sydney University for their support with the Illumian platform for MiSeq sequencing. We also thank Jasmine Grinyer for revising the English of this manuscript. This work was financially supported by UWS-CAS bilateral agreement and the Australian Research Council project DP13010484. M.D-B. also acknowledge support from the Marie SklodowskaCurie Actions of the Horizon 2020 Framework Programme H2020-MSCA-IF-2016 under REA grant agreement $n^{\circ}$ 702057. The authors declare no competing financial interests. 


\section{Appendix A. Supplementary data}

\section{Supplementary data related to this article can be found at http://} dx.doi.org/10.1016/j.soilbio.2016.12.003.

\section{References}

Allison, S.D., Czimczik, C.I., Treseder, K.K., 2008. Microbial activity and soil respiration under nitrogen addition in Alaskan boreal forest. Global Change Biology $14,1156-1168$.

Anderson, T.-H., Domsch, K.H., 1989. Ratios of microbial biomass carbon to total organic carbon in arable soils. Soil Biology and Biochemistry 21, 471-479.

Bardgett, R.D., van der Putten, W.H., 2014. Belowground biodiversity and ecosystem functioning. Nature 515, 505-511.

Bates, S.T., Donna, B.-L., Lauber, C.L., Walters, W.A., Knight, R., Fierer, N., 2012. A preliminary survey of lichen associated eukaryotes using pyrosequencing. The Lichenologist 44, 137-146.

Battistuzzi, F.U., Hedges, S.B., 2009. A major clade of prokaryotes with ancient adaptations to life on land. Molecular Biology and Evolution 26, 335-343.

Bell, T., Newman, J.A., Silverman, B.W., Turner, S.L., Lilley, A.K., 2005. The contribution of species richness and composition to bacterial services. Nature 436, 1157-1160.

Belnap, J., 2003. Factors Influencing Nitrogen Fixation and Nitrogen Release in Biological Soil Crusts, Biological Soil Crusts: Structure, Function, and Management. Springer, pp. 241-261.

Berg, G., Smalla, K., 2009. Plant species and soil type cooperatively shape the structure and function of microbial communities in the rhizosphere. FEMS Microbiology Ecology 68, 1-13.

Bodelier, P.L., 2011. Toward understanding, managing, and protecting microbial ecosystems. Frontiers in Microbiology 2.

Bowker, M.A., Belnap, J., 2008. A simple classification of soil types as habitats of biological soil crusts on the Colorado Plateau, USA. Journal of Vegetation Science 19, 831-840.

Brookes, P.C., Landman, A., Pruden, G., Jenkinson, D., 1985. Chloroform fumigation and the release of soil nitrogen: a rapid direct extraction method to measure microbial biomass nitrogen in soil. Soil Biology and Biochemistry 17, 837-842.

Canfora, L., Bacci, G., Pinzari, F., Papa, G.L., Dazzi, C., Benedetti, A., 2014. Salinity and bacterial diversity: to what extent does the concentration of salt affect the bacterial community in a saline soil? PLoS One 9, e106662.

Canfora, L., Vendramin, E., Antisari, L.V., Papa, G.L., Dazzi, C., Benedetti, A., Iavazzo, P., Adamo, P., Jungblut, A.D., Pinzari, F., 2016. Compartmentalization of gypsum and halite associated with cyanobacteria in saline soil crusts. FEMS Microbiology Ecology 92, fiw080.

Cregger, M.A., Schadt, C.W., McDowell, N.G., Pockman, W.T., Classen, A.T., 2012. Response of the soil microbial community to changes in precipitation in a semiarid ecosystem. Applied and Environmental Microbiology 78, 8587-8594.

Delgado-Baquerizo, M., Maestre, F.T., Gallardo, A., 2013. Biological soil crusts increase the resistance of soil nitrogen dynamics to changes in temperatures in a semi-arid ecosystem. Plant and Soil 366, 35-47.

Delgado-Baquerizo, M., Maestre, F.T., Gallardo, A., Eldridge, D.J., Soliveres, S., Bowker, M.A., Prado-Comesaña, A., Gaitán, J., Quero, J.L., Ochoa, V., Gozalo, B. García-Gómez, M., García-Palacios, P., Berdugo, M., Valencia, E., Escolar, C., Arredondo, T., Barraza-Zepeda, C., Boeken, B.R., Bran, D., Cabrera, O., Carreira, J.A., Chaieb, M., Conceição, A.A., Derak, M., Ernst, R., Espinosa, C.I., Florentino, A., Gatica, G., Ghiloufi, W., Gómez-González, S., Gutiérrez, J.R., Hernández, R.M., Huber-Sannwald, E., Jankju, M., Mau, R.L., Miriti, M. Monerris, J., Morici, E., Muchane, M., Naseri, K., Pucheta, E., Ramírez, E., Ramírez-Collantes, D.A., Romão, R.L., Tighe, M., Torres, D., Torres-Díaz, C., Val, J., Veiga, J.P., Wang, D., Yuan, X., Zaady, E., 2016a. Human impacts and aridity differentially alter soil N availability in drylands worldwide. Global Ecology and Biogeography 25, 36-45.

Delgado-Baquerizo, M., Maestre, F.T., Reich, P.B., Jeffries, T.C., Gaitan, J.J., Encinar, D., Berdugo, M., Campbell, C.D., Singh, B.K., 2016b. Microbial diversity drives multifunctionality in terrestrial ecosystems. Nature Communications 7.

Delgado-Baquerizo, M., Maestre, F.T., Eldridge, D.J., Bowker, M.A., Ochoa, V., Gozalo, B., Berdugo, M., Val, J., Singh, B.K., 2016c. Biocrust-forming mosses mitigate the negative impacts of increasing aridity on ecosystem multifunctionality in drylands. New Phytologist 209, 1540-1552.

Edgar, R.C., 2013. UPARSE: highly accurate OTU sequences from microbial amplicon reads. Nature Methods 10, 996-998.

Elbert, W., Weber, B., Burrows, S., Steinkamp, J., Büdel, B., Andreae, M.O., Pöschl, U., 2012. Contribution of cryptogamic covers to the global cycles of carbon and nitrogen. Nature Geoscience 5, 459-462.

Eldridge, D., Greene, R., 1994. Microbiotic soil crusts-a review of their roles in soil and ecological processes in the rangelands of Australia. Soil Research 32, 389-415.

Escolar, C., Maestre, F.T., Rey, A., 2015. Biocrusts modulate warming and rainfall exclusion effects on soil respiration in a semi-arid grassland. Soil Biology and Biochemistry 80, 9-17.

Ferrenberg, S., Reed, S.C., Belnap, J., 2015. Climate change and physical disturbance cause similar community shifts in biological soil crusts. Proceedings of the National Academy of Sciences.

Fierer, N., Bradford, M.A., Jackson, R.B., 2007. Toward an ecological classification of soil bacteria. Ecology 88, 1354-1364.

Fog, K., 1988. The effect of added nitrogen on the rate of decomposition of organic matter. Biological Reviews 63, 433-462.

Grace, J.B., 2006. Structural Equation Modeling and Natural Systems. Cambridge University Press.

Hector, A., Schmid, B., Beierkuhnlein, C., Caldeira, M., Diemer, M., Dimitrakopoulos, P., Finn, J., Freitas, H., Giller, P., Good, J., 1999. Plant diversity and productivity experiments in European grasslands. Science 286, 1123-1127.

Herlemann, D.P., Labrenz, M., Jürgens, K., Bertilsson, S., Waniek, J.J., Andersson, A.F 2011. Transitions in bacterial communities along the $2000 \mathrm{~km}$ salinity gradient of the Baltic Sea. The ISME Journal 5, 1571-1579.

Hug, L.A., Castelle, C.J., Wrighton, K.C., Thomas, B.C., Sharon, I., Frischkorn, K.R., Williams, K.H., Tringe, S.G., Banfield, J.F., 2013. Community genomic analyses constrain the distribution of metabolic traits across the Chloroflexi phylum and indicate roles in sediment carbon cycling. Microbiome $1,1$.

Jiao, N., Herndl, G.J., Hansell, D.A., Benner, R., Kattner, G., Wilhelm, S.W. Kirchman, D.L., Weinbauer, M.G., Luo, T., Chen, F., 2010. Microbial production of recalcitrant dissolved organic matter: long-term carbon storage in the global ocean. Nature Reviews Microbiology 8, 593-599.

Jing, X., Sanders, N.J., Shi, Y., Chu, H., Classen, A.T., Zhao, K., Chen, L., Shi, Y., Jiang, Y. He, J.-S., 2015. The links between ecosystem multifunctionality and above- and belowground biodiversity are mediated by climate. Nature Communications 6 .

Kidron, G.J., Posmanik, R., Brunner, T., Nejidat, A., 2015. Spatial abundance of microbial nitrogen-transforming genes and inorganic nitrogen in biocrusts along a transect of an arid sand dune in the Negev Desert. Soil Biology and Biochemistry 83, 150-159.

Kraft, B., Tegetmeyer, H.E., Sharma, R., Klotz, M.G., Ferdelman, T.G., Hettich, R.L, Geelhoed, J.S., Strous, M., 2014. The environmental controls that govern the end product of bacterial nitrate respiration. Science 345, 676-679.

Liu, Y.-R., Delgado-Baquerizo, M., Trivedi, P., He, J.-Z., Singh, B.K., 2016. Species identity of biocrust-forming lichens drives the response of soil nitrogen cycle to altered precipitation frequency and nitrogen amendment. Soil Biology and Biochemistry 96, 128-136.

Maestre, F.T., Castillo-Monroy, A.P., Bowker, M.A., Ochoa-Hueso, R., 2012a. Species richness effects on ecosystem multifunctionality depend on evenness, composition and spatial pattern. Journal of Ecology 100, 317-330.

Maestre, F.T., Delgado-Baquerizo, M., Jeffries, T.C., Eldridge, D.J., Ochoa, V., Gozalo, B. Quero, J.L., García-Gómez, M., Gallardo, A., Ulrich, W., Bowker, M.A., Arredondo, T., Barraza-Zepeda, C., Bran, D., Florentino, A., Gaitán, J., Gutiérrez, J.R., Huber-Sannwald, E., Jankju, M., Mau, R.L., Miriti, M., Naseri, K., Ospina, A., Stavi, I., Wang, D., Woods, N.N., Yuan, X., Zaady, E., Singh, B.K., 2015a. Increasing aridity reduces soil microbial diversity and abundance in global drylands. Proceedings of the National Academy of Sciences 112, 15684-15689.

Maestre, F.T., Escolar, C., Bardgett, R.D., Dungait, J.A.J., Gozalo, B., Ochoa, V., 2015b. Warming reduces the cover and diversity of biocrust-forming mosses and lichens, and increases the physiological stress of soil microbial communities in a semi-arid Pinus halepensis plantation. Frontiers in Microbiology 6, 865.

Maestre, F.T., Escolar, C., Guevara, M.L., Quero, J.L., Lázaro, R., Delgado-Baquerizo, M., Ochoa, V., Berdugo, M., Gozalo, B., Gallardo, A., 2013. Changes in biocrust cover drive carbon cycle responses to climate change in drylands. Global Change Biology 19, 3835-3847.

Maestre, F.T., Quero, J.L., Gotelli, N.J., Escudero, A., Ochoa, V., Delgado-Baquerizo, M., García-Gómez, M., Bowker, M.A., Soliveres, S., Escolar, C., 2012b. Plant species richness and ecosystem multifunctionality in global drylands. Science 335, 214-218.

Magoč, T., Salzberg, S.L., 2011. FLASH: fast length adjustment of short reads to improve genome assemblies. Bioinformatics 27, 2957-2963.

Maier, S., Schmidt, T.S.B., Zheng, L., Peer, T., Wagner, V., Grube, M., 2014. Analyses of dryland biological soil crusts highlight lichens as an important regulator of microbial communities. Biodiversity and Conservation 23, 1735-1755.

Martins, C.S.C., Nazaries, L., Macdonald, C.A., Anderson, I.C., Singh, B.K., 2015. Water availability and abundance of microbial groups are key determinants of greenhouse gas fluxes in a dryland forest ecosystem. Soil Biology and Biochemistry 86, 5-16.

McDonald, D., Price, M.N., Goodrich, J., Nawrocki, E.P., DeSantis, T.Z., Probst, A Andersen, G.L., Knight, R., Hugenholtz, P., 2012. An improved Greengenes taxonomy with explicit ranks for ecological and evolutionary analyses of bacteria and archaea. The ISME Journal 6, 610-618.

McGill, W., Cole, C., 1981. Comparative aspects of cycling of organic C, N, S and P through soil organic matter. Geoderma 26, 267-286.

Peter, H., Beier, S., Bertilsson, S., Lindström, E.S., Langenheder, S., Tranvik, L.J., 2011. Function-specific response to depletion of microbial diversity. The ISME Journal 5, 351-361.

Philippot, L., Andersson, S.G.E., Battin, T.J., Prosser, J.I., Schimel, J.P., Whitman, W.B. Hallin, S., 2010. The ecological coherence of high bacterial taxonomic ranks. Nature Review Microbiology 8, 523-529.

Ramirez, K.S., Craine, J.M., Fierer, N., 2012. Consistent effects of nitrogen amendments on soil microbial communities and processes across biomes. Global Change Biology 18, 1918-1927.

Ramirez, K.S., Lauber, C.L., Knight, R., Bradford, M.A., Fierer, N., 2010. Consistent effects of nitrogen fertilization on soil bacterial communities in contrasting systems. Ecology 91, 3463-3470.

Reed, S.C., Coe, K.K., Sparks, J.P., Housman, D.C., Zelikova, T.J., Belnap, J., 2012. Changes to dryland rainfall result in rapid moss mortality and altered soil fertility. Nature Climate Change 2, 752-755. 
Reynolds, J.F., Smith, D.M.S., Lambin, E.F., Turner, B., Mortimore, M., Batterbury, S.P. Downing, T.E., Dowlatabadi, H., Fernández, R.J., Herrick, J.E., 2007. Global desertification: building a science for dryland development. Science 316, $847-851$.

Roose, T., Keyes, S., Daly, K., Carminati, A., Otten, W., Vetterlein, D., Peth, S., 2016 Challenges in imaging and predictive modeling of rhizosphere processes. Plant and Soil 1-30.

Sancho, L.G., Maestre, F.T., Büdel, B., 2014. Biological soil crusts in a changing world: introduction to the special issue. Biodiversity and Conservation 23, 1611-1617.

Schermelleh-Engel, K., Moosbrugger, H., Müller, H., 2003. Evaluating the fit of structural equation models: tests of significance and descriptive goodness-of-fit measures. Methods of Psychological Research Online 8, 23-74.

Singh, B.K., Bardgett, R.D., Smith, P., Reay, D.S., 2010. Microorganisms and climate change: terrestrial feedbacks and mitigation options. Nature Reviews Microbiology 8, 779-790.

Sinsabaugh, R.L., Belnap, J., Rudgers, J., Kuske, C.R., Martinez, N., Sandquist, D., 2015. Soil microbial responses to nitrogen addition in arid ecosystems. Frontiers in Microbiology 6.

Solomon, S., 2007. Climate Change 2007-the Physical Science Basis: Working Group I Contribution to the Fourth Assessment Report of the IPCC. Cambridge University Press.

Tedersoo, L., Bahram, M., Põlme, S., Kõljalg, U., Yorou, N.S., Wijesundera, R. Ruiz, L.V., Vasco-Palacios, A.M., Thu, P.Q., Suija, A., 2014. Global diversity and geography of soil fungi. Science 346, 1256688.

Tilman, D., Reich, P.B., Knops, J., Wedin, D., Mielke, T., Lehman, C., 2001. Diversity and productivity in a long-term grassland experiment. Science 294, 843-845.

Tilman, D., Wedin, D., Knops, J., 1996. Productivity and sustainability influenced by biodiversity in grassland ecosystems. Nature 379, 718-720.

Trivedi, P. Anderson, I.C. Singh, B.K., 2013. Microbial modulators of soil carbon storage: integrating genomic and metabolic knowledge for global prediction. Trends in Microbiology 21, 641-651.

Trivedi, P., Delgado-Baquerizo, M., Trivedi, C., Hu, H., Anderson, I.C., Jeffries, T.C., Zhou, J., Singh, B.K., 2016. Microbial regulation of the soil carbon cycle: evidence from gene-enzyme relationships. The ISME Journal 10, 2593-2604.

Vance, E.D., Brookes, P.C., Jenkinson, D.S., 1987. An extraction method for measuring soil microbial biomass C. Soil Biology and Biochemistry 19, 703-707.

Wagg, C., Bender, S.F., Widmer, F., van der Heijden, M.G.A., 2014. Soil biodiversity and soil community composition determine ecosystem multifunctionality. Proceedings of the National Academy of Sciences 111, 5266-5270.

Walker, T., Syers, J.K., 1976. The fate of phosphorus during pedogenesis. Geoderma $15,1-19$.

Wallenstein, M.D., Weintraub, M.N., 2008. Emerging tools for measuring and modeling the in situ activity of soil extracellular enzymes. Soil Biology and Biochemistry 40, 2098-2106.

Wardle, D.A., Bardgett, R.D., Klironomos, J.N., Setälä, H., Van Der Putten, W.H., Wall, D.H., 2004. Ecological linkages between aboveground and belowground biota. Science 304, 1629-1633.

Yoshitake, S., Uchida, M., Koizumi, H., Kanda, H., Nakatsubo, T., 2010. Production of biological soil crusts in the early stage of primary succession on a High Arctic glacier foreland. New Phytologist 186, 451-460.

Zeglin, L., Bottomley, P.J., Jumpponen, A., Rice, C., Arango, M., Lindsley, A., McGowan, A., Mfombep, P., Myrold, D., 2013. Altered precipitation regime affects the function and composition of soil microbial communities on multiple time scales. Ecology 94, 2334-2345. 